\title{
Phyllosomas of smooth fan lobsters (Ibacus novemdentatus) encase jellyfish cnidae in peritrophic membranes in their feces
}

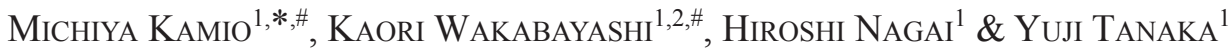 \\ ${ }^{1}$ Tokyo University of Marine Science and Technology, Minato, Tokyo, 108-8477, Japan \\ ${ }^{2}$ Graduate School of Biosphere Science, Hiroshima University, Higashi-hiroshima, Hiroshima, 739-8528, Japan
}

Received 3 April 2016; Accepted 24 June 2016 Responsible Editor: Dhugal Lindsay

\begin{abstract}
Jellyfish possess venomous cnidae on their tentacles to capture and consume marine zooplankton. Nevertheless, the planktonic larvae of the smooth fan lobster (Ibacus novemdentatus), known as phyllosoma, prey on jellyfish and successfully ingest both tentacle tissue as well as constituent cnidae, despite the presence of the venom-filled explosively penetrant cnidae or nematocysts. In the present study, we hypothesized that phyllosomas have mechanical and/or physiological resistance to internal envenomation by ingested nematocysts. To test this hypothesis, we examined the feces of phyllosomas $(n=5)$ that were fed with Japanese sea nettle (Chrysaora pacifica) and found both undischarged as well as discharged cnidae surrounded by peritrophic membrane. We surmise that this membrane may mechanically insulate the lining of the midgut from stinging nematocysts to avoid injection of jellyfish venom into the phyllosomas' body by nematocyst tubule penetration. We then tested physiological sensitivity of the phyllosomas $(\mathrm{n}=10)$ to crude extract of tentacle cnidae injected into their bodies. For this experiment, we used a crude venom extract prepared from nematocysts isolated from tentacles of a rhizostome jellyfish (Nemopilema nomurai) after exposure to high salt which disrupted tentacle integrity, and phosphate-buffered saline as a control. Nine out of 10 animals died after the injection of crude venom extract, while none of the animals died in the control group. These results indicate that the defense of phyllosoma larvae against the toxin of jellyfish is a combination of mechanical inactivation of the ingested nematocysts and chemical digestion of the toxin in the midgut rather than physiological resistance against the toxin.
\end{abstract}

Key words: feeding ecology, nematocyst, plankton, Scyphozoa, toxin, venom

Jellyfish consume planktonic crustaceans such as copepods (Ishii \& Tanaka 2001) and shrimp (Carrette et al. 2002) utilizing various types of tentacle cnidae including penetrant, venom-filled nematocysts (Tardent 1995, Nagai 2012, Ponce et al. 2013). During nematocyst discharge, venom-filled tubules explosively penetrate the cuticle of the prey (Tardent $\&$ Holstein 1982, Purcell 1984) and inject their venom through the tubules (Lotan et al. 1996, Yanagihara et al. 2002). Despite the potency of venom in jellyfish, phyllosomas of spiny (Palinuridae) and slipper (Scyllaridae) lobsters often associate with gelatinous zooplankton, including jellyfish (Booth et al. 2005, Ates et al. 2007, Ohtsuka et al. 2009, O’Rorke et al. 2014). Indeed the phyllosomas of Ibacus novemdentatus Gibbes, 1850 (Decapoda: Achelata: Scyllaridae) have been reported to ride and prey on cnidarian jellyfish in the wild (Shojima 1963). In the laboratory, planktonic-phase phyllosomas were fed exclusively moon jellyfish (Aurelia aurita s.1.) (Wakabayashi et al. 2012b). The phyllosomas can consume a

\footnotetext{
\# These authors equally contributed.

* Corresponding author: Michiya Kamio; E-mail, mkamio@kaiyodai. ac.jp
}

variety of jellyfish (Wakabayashi et al. 2012a), including species harmful to humans because their long tubules can penetrate our skin (e.g., Carybdea brevipedalia Kishinouye, 1981) (Kitatani et al. 2015). Phyllosomas attach to the exumbrella of jellyfish and consume all of the tentacles, then eat the rest of the body (Wakabayashi et al. 2012a). By consuming tentacles, phyllosomas introduce nematocysts into their digestive tracts and consequently risk internal envenomation by the ingested nematocysts. Potential protective mechanisms to circumvent this could include 1) specialized digestive tract lumen surfaces acting as a physical barrier to nematocyst discharge, or 2) phyllosomas' immunity to the venom injected in their body. Hindgut and foregut in crustaceans are cuticle-lined and thus mechanically protected (Mikami \& Takashima 1993, Greenaway 2001). In contrast, the midgut is not cuticle-lined (Mikami et al. 1994) and thus relatively vulnerable. There are three possible mechanisms whereby phyllosomas can feed on intact nematocyst-loaded tentacles of jellyfish. The first is to ingest the nematocysts without inducing discharge, as aeolid nudibranchs do. Nudibranchs prey on cnidarians and sequester the nematocysts (Edmunds 2009) into defensive organs-the kleptocnidae (Garese et al. 2012). In this case, nudibranchs 
ingest intact nematocysts without making them discharge and send them through the digestive system to form kleptocnidae on their body surface. The second mechanism is encasing nematocysts in a peritrophic membrane (Lehane 1997) to mechanically protect the midgut. The peritrophic membrane is present in adult Scyllaridae (Johnston \& Alexander 1999). A third potential mechanism is to have physiological resistance to injected venom, which could be obtained through mutations of target proteins making them resistant to the venomous molecules (Barchan et al. 1992, Voss \& Jansa 2012). Defensive molecules in hemolymph (Fredrick \& Ravichandran 2012) might play a role to neutralize the venom. To explore these hypotheses of possible mechanisms of phyllosomas' tolerance to jellyfish venom, we examined if: (1) nematocysts of Japanese sea nettle Chrysaora pacifica (Goette, 1886) in the feces of phyllosomas are discharged; (2) if nematocysts in the feces are surrounded by peritrophic membrane; and (3) if phyllosomas are tolerant to crude extract from venom of the rhizostome jellyfish Nemopilema nomurai Kishinouye, 1922. A coherent study, using one species of jellyfish would have been ideal, however three different species of jellyfish were used due to physical and operational constraints combined with a limited number of cultured phyllosomas in this study; A. aurita s.l. was used as food because it is abundant enough for culturing phyllosoma, C. pacifica was used for observation of feces, N. nomurai was used for preparation of crude venom, because it provided the amounts of tentacles necessary for the experiments.

An ovigerous female of Ibacus novemdentatus (carapace length $65 \mathrm{~mm}$ ) was purchased from commercial fisherman in Hirado, Nagasaki Prefecture, Japan, and kept in a recirculating tank system. Phyllosomas derived from the ovigerous female were collected from the tank and reared individually using mesh cases as described elsewhere (Wakabayashi et al. 2016). We defined stage I as the phyllosoma immediately after hatching, stage II as the phyllosoma after first molt, and stage III as the phyllosoma after the second molt, and so on. Each stage in the phyllosoma phase (Sekiguchi et al. 2007) is usually associated with a single instar in I. novemdentatus (Wakabayashi \& Tanaka 2012).

To observe nematocysts in feces, fresh tentacles removed from C. pacifica were used because live individuals are available from Tokyo Bay as described elsewhere (Wakabayashi et al. 2012b). C. pacifica was selected from the species that are available in Tokyo Bay for this purpose because the morphology of their nematocysts can be readily observed using light microscopy. Five of the phyllosomas at stages either V or VI were starved until their digestive tracts were void. The phyllosomas were fed with the tentacles and observed for a few hours until they passed feces. The feces were collected by pipet from the bottom of the mesh cases and viewed under a microscope (BX-50W, Olympus).

In an effort to assess a potential host resistance, the physiological response of phyllosomas to injected venom was examined. Crude venom extract was prepared from tentacle nematocysts of $N$. nomurai. Excised $N$. nomurai tentacles $(10 \mathrm{ml})$ were added to $20 \mathrm{ml}$ of $3 \mathrm{M} \mathrm{NaCl}$ and kept at $4^{\circ} \mathrm{C}$ for three days, at which point tentacle integrity was lost to yield a cell and cnidae slurry. This solution was filtered through a nylon stocking prior to centrifugation of the filtrate at $1,100 \times g$ for $30 \mathrm{~min}$. The pellet from the centrifugation containing nematocysts was used to extract venom. A weight of $0.5 \mathrm{~g}$ (wet) of the nematocyst pellet was mixed with $1.0 \mathrm{~g}$ of glass beads of diameter $0.5 \mathrm{~mm}$ and $1 \mathrm{ml}$ of $10 \mathrm{mM}$ phosphate buffer $\mathrm{pH} 7.0$ in a plastic tube equipped with a mini-bead beater (BioSpec Products, Bartlesville). To extract the venom from intact nematocysts, the tube was agitated using the mini-bead beater at 4,800 oscillations/min for $30 \mathrm{~s}$ and cooled down on ice for 30 s (Carrette \& Seymour 2004). This procedure was repeated ten times. Extracted venomous liquid was collected from the tube by pipet, brought up to $1.3 \mathrm{ml}$ with $10 \mathrm{mM}$ phosphate buffer $\mathrm{pH}$ 7.0, and used as crude venom extract. The crude venom extract was injected using a syringe (SuperFlex 51823496, Agilent) into the abdominal muscle of the phyllosomas $(n=10)$ from the ventral side at a dose of $3 \mu$ crude venom extract per g body weight. Individuals that were injected with the phosphate buffer were used as a 'sham' control. The movements of appendages, including pereiopods and third maxillipeds, were observed by eye for $1.5 \mathrm{~h}$, then every $20 \mathrm{~min}$ up to $5 \mathrm{~h}$ after the injection. Animals that survived were observed again $24 \mathrm{~h}$ after the injection. This experiment could not be blind because the injected crude venom extract was not transparent and appeared different from the phosphate buffer. Numbers of animals that died within $24 \mathrm{~h}$ were compared between a test and a control using a two-tailed sign test at a significance level of $5 \%$ in the statistical program R (R Foundation for Statistical Computing) (http://www.r-project.org) version 3.0.2. N. nomurai individuals were collected from the Sea of Japan with the research vessel Kaiyo-maru No. 7 (lat. $38^{\circ} 00^{\prime}$ to $37^{\circ} 30^{\prime} \mathrm{N}$ and long. $137^{\circ} 30^{\prime}$ to $138^{\circ} 30^{\prime} \mathrm{E}$ ) using an LCnet (larvae catcher, Nichimo Ltd.), with $10 \times 10 \mathrm{~m}$ of mouth opening and $30 \times 30 \mathrm{~mm}$ of mesh opening, including cod-end, that was horizontally towed at a depth of $10 \mathrm{~m}$ for $5 \mathrm{~min}$ at a constant speed of $1 \mathrm{~m} / \mathrm{s}$. We used the largest phyllosomas at stage VI (weight $0.40-0.79 \mathrm{~g}$ ) as smaller animals may not be tolerant of physical damage caused by the syringe needle during the injection.

Our observations of feces from five phyllosomas were consistent with the observation of discharged nematocysts in feces from wild-caught scyllarid phyllosoma by Sims Jr. and Brown Jr. (1968). The nematocysts in the feces (Fig. 1A, B) were discharged and covered by a sheath-like material; we interpret this to be a peritrophic membrane. Peritrophic membranes are non-cellular secreted layers that separate ingested material from the gut epithelium. In insects and crustaceans, peritrophic membranes are produced in the midgut trunk (Martin et al. 2006). Nematocyst tubules were not observed on the outer surface of the peritrophic membrane (Fig. 1A), indicating that the tubules do not penetrate the membrane and that the membranes function as a mechanical barrier to protect the midgut from nematocysts. The proportion of nematocysts that were discharged in the midgut could not be 


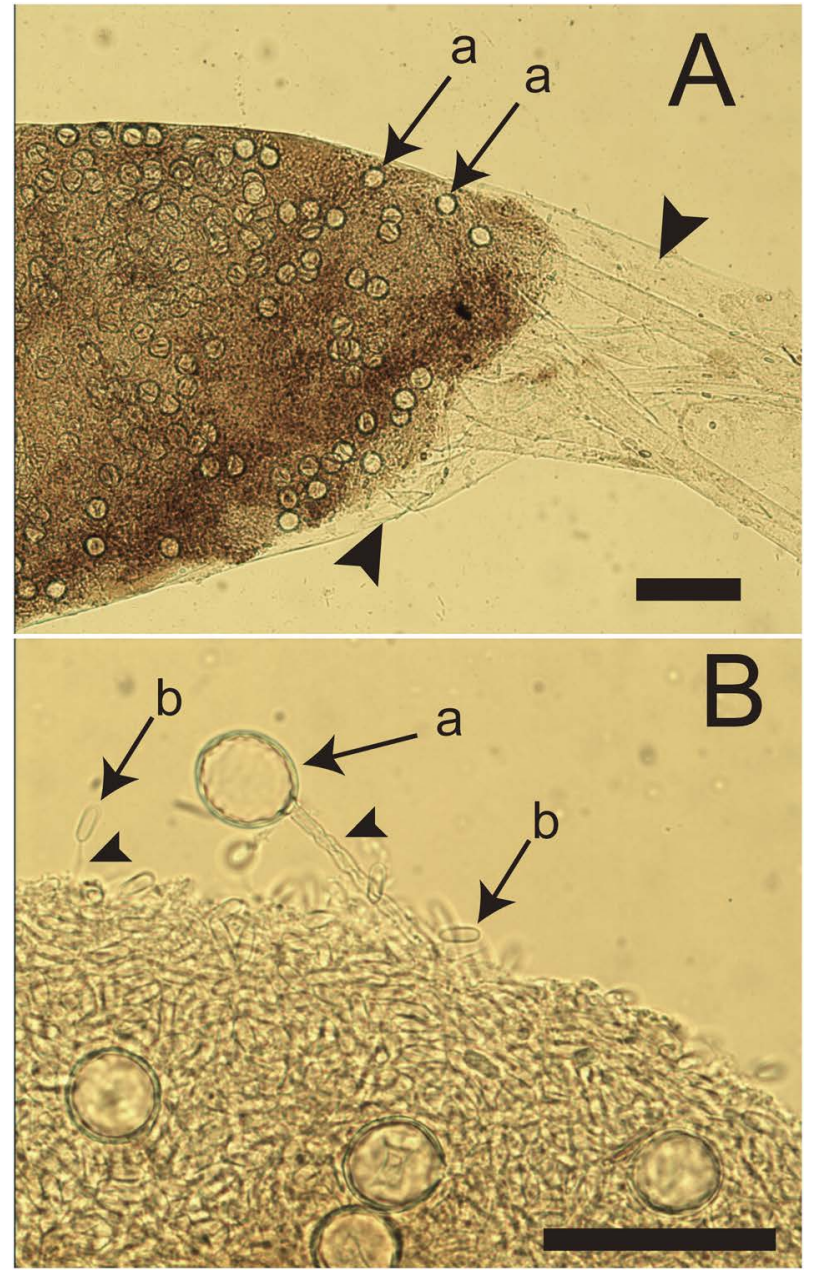

Fig. 1. Light microscopic images of feces of phyllosoma. A: Feces. Scale bar is $100 \mu \mathrm{m}$. Within the feces, nematocysts (a), are encased in a peritrophic membrane (arrowheads). B: Contents of feces. Scale bar is $50 \mu \mathrm{m}$. The peritrophic membrane of the feces was torn using forceps, and the contents of the feces were observed. Nematocyst tubules, which are discharged from the nematocyst capsule (indicated by arrows a, b), are indicated by arrowheads. There are at least two types of nematocysts, having either large capsule (a) or small capsule (b), and some part of both of them is discharged. A zoomed-out image mosaic of this fecal matter is available as a supplemental figure (https://www.jstage.jst.go.jp/ browse/pbr).

determined because various stimuli that occur during experimental manipulation before their ingestion and after their egestion can induce discharge; however, even if a small portion of discharge occurs in the midgut, discharged proteinous venoms (Nagai 2012) may not be highly toxic in the midgut as they may be enzymatically digested, and toxicity inactivated before being absorbed into the digestive gland.

In our venom-injection experiment, the ratio of the wet weight of nematocysts used for the extraction of crude venom, to the phyllosoma's wet weight was $0.12 \%$. Since generally, the volume of hemolymph in crustaceans is $30.6 \%$ of the body weight (weight /weight), the ratio of nematocyst wet weight to hemolymph wet weight was $0.38 \%$. For example, a
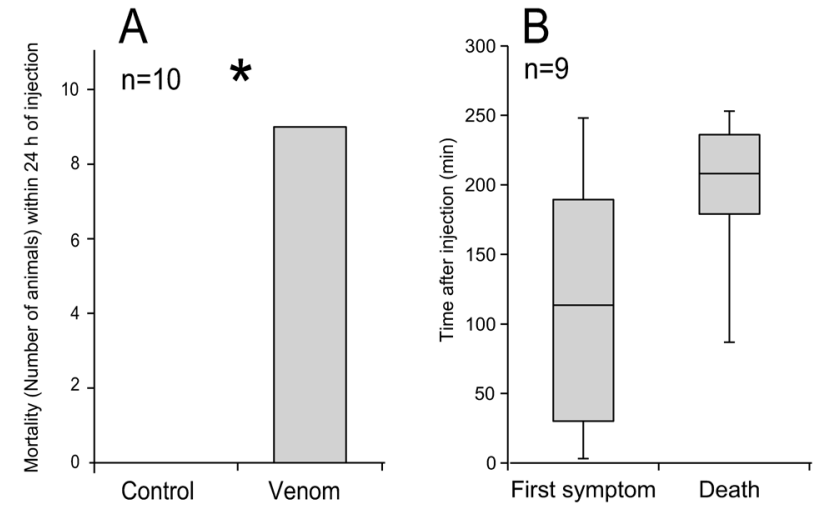

Fig. 2. Responses of the phyllosomas to venom injection. A: Number of phyllosomas of Ibacus novemdentatus that died within $24 \mathrm{~h}$ of injection with crude venom extract from Nemopilema nomurai and phosphate buffer as control. * significant difference $(P<0.01$ by two-tailed Sign test). B: Boxplot of latency to show first symptom of intoxication and to death after injection of crude venom extract from $N$. nomurai. Values are medians, interquartile ranges, minima, and maxima.

$500 \mathrm{mg}$ phyllosoma was injected with crude venom extract from $580 \mu \mathrm{g}$ of nematocysts. This dose was selected as it was found sufficient to kill a freshwater shrimp in $20 \mathrm{~min}$ in a preliminary experiment. Before the injection, the phyllosomas were swimming by continuous fanning of pereiopodal exopods and grooming body surfaces by continuous motion of the third maxillipeds. Injection of crude venom extract extracted from the nematocysts of $N$. nomurai proved lethal to the phyllosomas. Within $24 \mathrm{~h}$ of injection of the crude venom extract, $90 \%$ of the phyllosomas $(n=10)$ died, as determined by a complete lack of movement (Fig. 2A). In contrast, all phyllosomas $(n=10)$ survived injection of the phosphatebuffered saline. The difference between these two groups of animals was significant $(P<0.05, Z=-2.89$ by Sign test). The latency to show the first symptoms, being intermittent stoppage of fanning of pereiopodal exopods, ranged from 3 to $248 \mathrm{~min}$. The median value of the latency was $83.5 \mathrm{~min}$. The first and the last dead individuals were observed $87 \mathrm{~min}$ and $253 \mathrm{~min}$ after the injection of crude venom extract, respectively. The median value of time to die was $208 \mathrm{~min}$ (Fig. 2B). Grooming was more persistent than fanning, and in all cases grooming started to decline following termination of the fanning movement. Additionally, one phyllosoma that showed a reduction in fanning recovered without showing any changes in grooming, and survived to complete all planktonic stages. Therefore, persistent grooming by the third maxillipeds might be responsible for maintaining their basic biological activities such as respiration (Kamio et al. 2015). Individuals injected with phosphate buffer showed no changes in their behavior during the observation period.

Thus, no systemic protective response, including neutralizing resistance, was observed in the phyllosomas of I. novemdentatus upon exposure to injected jellyfish crude venom extract. In contrast, evidence was observed to support digestive tract mechanisms to evade internal envenomation by ingested 
nematocysts during digestion. In addition to the digestive adaptation of the peritrophic membrane, phyllosomas exhibit other adaptive characteristics to facilitate stable associations with planktonic jellyfish. To stay on and consume jellyfish, the phyllosomas grip and manipulate jellyfish by pointed dactyli at the ends of their pereiopods (Wakabayashi et al. 2012a). Similar morphological adaptations occur in hyperiid amphipods: they have hook-like structures on the dactyli to catch gelatinous animals (Laval 1980). Continuous grooming behavior using the elongated third maxillipeds is a strategy to avoid fouling by mucus secreted from jellyfish (Kamio et al. 2015). In addition to behavioral aspects, the mechanism of prey processing may eliminate envenomation by ingested nematocysts. The phyllosomas have a filter-press structure to consume the body fluid of prey, and which permits only fluids and the finest particles (e.g. $1 \mu \mathrm{m}$ in diameter in spiny lobster Sagmariasus verreauxi (H. Milne Edwards, 1851) to enter the digestive gland (Johnston \& Alexander 1999, Simon et al. 2012). Therefore, the filter-press might mechanically prevent nematocysts [large ones have $10 \mu \mathrm{m}$ diameter (Östman 2000)] from entering the digestive gland. Through a combination of behavioral and morphological adaptations phyllosomas avoid envenomation by jellyfish nematocysts.

The present study used two species of jellyfish that cooccur with the phyllosomas of Ibacus novemdentatus, and thus our results should reflect ecologically-relevant predatorprey interactions. However, since each jellyfish species was used to test only one of the hypothetical mechanisms, future studies should use each tested jellyfish species in all assays. In addition, the mechanisms of action of the jellyfish venoms require investigation as phyllosomas may also have biochemical adaptations to cope with envenomation.

\section{Acknowledgements}

We thank Dr. Charles Derby at Georgia State University for reading our manuscript, correcting English, and valuable discussions. Collection of jellyfish was made possible by support from the training ship Hiyodori of Tokyo University of Marine Science and Technology and the research vessel Kaiyo-maru No. 7 of Nihon Kaiyo Co. Ltd. The present study was supported by JSPS KAKENHI Grants-in-Aid for JSPS Fellows $(25 \cdot 10983)$ and Grants-in-Aid for Young Scientist B (26850121) to K.W., the Program for Promotion of Basic and Applied Researches for Innovations in Biooriented Industry to Y.T., JSPS Grant-in-Aid for Scientific Research Grant (24510294) to H.N., and Research Promotion for Marine Science and Technology in Tokyo University of Marine Science and Technology to Y.T. M.K. was supported by an internal grant from Tokyo University of Marine Science and Technology.

\section{Competing interests}

No competing interests declared.

\section{References}

Ates R, Lindsay DJ, Sekiguchi H (2007) First record of an association between a phyllosoma larva and a prayid siphonophore. Plankton Benthos Res 2: 67-69.

Barchan D, Kachalsky S, Neumann D, Vogel Z, Ovadia M, Kochva E, Fuchs S (1992) How the mongoose can fight the snake: the binding site of the mongoose acetylcholine receptor. Proc Natl Acad Sci USA 89: $7717-7721$.

Booth JD, Webber WR, Sekiguchi H, Coutures E (2005) Diverse larval recruitment strategies within the Scyllaridae. N Z J Mar Freshwater Res 39: 581-592.

Carrette T, Alderslade P, Seymour J (2002) Nematocyst ratio and prey in two Australian cubomedusans, Chironex fleckeri and Chiropsalmus sp. Toxicon 40: 1547-1551.

Carrette T, Seymour J (2004) A rapid and repeatable method for venom extraction from Cubozoan nematocysts. Toxicon 44: 135-139.

Edmunds M (2009) Do nematocysts sequestered by aeolid nudibranchs deter predators? - a background to the debate. J Molluscan Stud 75: 203-205.

Fredrick WS, Ravichandran S (2012) Hemolymph proteins in marine crustaceans. Asian Pacific J Tropic Biomed 2: 496-502.

Garese A, Garcia-Matucheski S, Acuna FH, Muniain C (2012) Feeding behavior of Spurilla sp. (Mollusca: Opisthobranchia) with a description of the kleptocnidae sequestered from its sea anemone prey. Zool Stud 51: 905-912.

Greenaway P (2001) The Crustacea. In: Invertebrate Zoology (eds Anderson DT). Oxford University Press Oxford, UK, pp. 292-324.

Ishii H, Tanaka F (2001) Food and feeding of Aurelia aurita in Tokyo Bay with an analysis of stomach contents and a measurement of digestion times. Hydrobiologia 451: 311-320.

Johnston DJ, Alexander CG (1999) Functional morphology of the mouthparts and alimentary tract of the slipper lobster Thenus orientalis (Decapoda: Scyllaridae). Mar Freshwater Res 50: 213-223.

Kamio M, Furukawa D, Wakabayashi K, Hiei K, Yano H, Sato H, Yoshie-Stark Y, Akiba T, Tanaka Y (2015) Grooming behavior by elongated third maxillipeds of phyllosoma larvae of the smooth fan lobster riding on jellyfishes. J Exp Mar Biol Ecol 463: 115-124.

Kitatani R, Yamada M, Kamio M, Nagai H (2015) Length is associated with pain: jellyfish with painful sting have longer nematocyst tubules than harmless jellyfish. PLoS ONE 10: e0135015.

Laval P (1980) Hyperiid amphipods as crustacean parasitoids associated with gelatinous zooplankton. In: Oceanography and Marine Biology-An Annual Review (eds Barnes M). Aberdeen University Press, Aberdeen, pp. 11-56.

Lehane MJ (1997) Peritrophic matrix structure and function. Annu Rev Entomol 42: 525-550.

Lotan A, Fishman L, Zlotkin E (1996) Toxin compartmentation and delivery in the Cnidaria: the nematocyst's tubule as a multiheaded poisonous arrow. J Exp Zool 275: 444-451.

Martin GG, Simcox R, Nguyen A, Chilingaryan A (2006) Peritrophic membrane of the penaeid shrimp Sicyonia ingentis: structure, formation, and permeability. Biol Bull 211: 275-285.

Mikami S, Greenwood JG, Takashima F (1994) Functional morphology and cytology of the phyllosomal digestive system of Ibacus ciliatus and Panulirus japonicus (Decapoda, Scyllaridae and Palinuridae). Crustaceana 67: 212-225.

Mikami S, Takashima F (1993) Development of the proventriculus in larvae of the slipper lobster, Ibacus ciliatus (Decapoda: Scyllaridae). Aquaculture 116: 199-217.

Nagai H (2012) Marine protein toxins. In: Handbook of Marine Natural Products (eds Fattorusso E, Gerwick WH, TaglialatelaScafati O). Springer, pp. 1388-1419.

O’Rorke R, Lavery SD, Wang M, Gallego R, Waite AM, Beckley LE, Thompson PA, Jeffs AG (2014) Phyllosomata associated with large gelatinous zooplankton: hitching rides and stealing bites. ICES J Mar 
Sci 72 (Supplement 1): i124-i127.

Ohtsuka S, Koike K, Lindsay D, Nishikawa J, Miyake H, Kawahara M, Mulyadi, Mujiono N, Hiromi J, Komatsu H (2009) Symbionts of marine medusae and ctenophores. Plankton Benthos Res 4: 1-13.

Östman C (2000) A guideline to nematocyst nomenclature and classification, and some notes on the systematic value of nematocysts. Scientia Marina 64: 31-46.

Ponce D, López-Vera E, Aguilar MB, Sánchez-Rodriguez J (2013) Preliminary results of the in vivo and in vitro characterization of a tentacle venom fraction from the jellyfish Aurelia aurita. Toxins 5: 2420-2433.

Purcell JE (1984) The functions of nematocysts in prey capture by epipelagic siphonophores (Coelenterata, Hydrozoa). Biol Bull 166: 310-327.

Sekiguchi H, Booth JD, Webber WR (2007) Early life histories of slipper lobsters. In: The Biology and Fisheries of the Slipper Lobster (eds Lavalli KL, Spanier E). CRC Press, Boca Raton, pp. 69-86.

Shojima Y (1963) Scyllarid phyllosomas' habit of accompanying the jelly-fish (preliminary report). Bull Jap Soc Sci Fish 29: 349-353.

Simon CJ, Carter CG, Battaglene SC (2012) Development and function of the filter-press in spiny lobster, Sagmariasus verreauxi, phyllosoma. Aquaculture 370: 68-75.

Sims Jr. HW, Brown Jr. CL (1968) A giant scyllarid phyllosoma larva taken north of Bermuda (Palinuridea). Crustaceana. Supplement: 80 82.

Tardent P (1995) The cnidarian cnidocyte, a high-tech cellular weap- onry. BioEssays 17: 351-362.

Tardent P, Holstein T (1982) Morphology and morphodynamics of the stenotele nematocyst of Hydra attenuata Pall. (Hydrozoa, Cnidaria). Cell Tissue Res 224: 269-290.

Voss RS, Jansa SA (2012) Snake-venom resistance as a mammalian trophic adaptation: lessons from didelphid marsupials. Biol Rev 87: 822-837.

Wakabayashi K, Nagai S, Tanaka Y (2016) The complete larval development of Ibacus ciliatus from hatching to the nisto and juvenile stages using jellyfish as the sole diet. Aquaculture 450: 102-107.

Wakabayashi K, Sato R, Hirai A, Ishii H, Akiba T, Tanaka Y (2012a) Predation by the phyllosoma larva of Ibacus novemdentatus on various kinds of venomous jellyfish. Biol Bull 222: 1-5.

Wakabayashi K, Sato R, Ishii H, Akiba T, Nogata Y, Tanaka Y (2012b) Culture of phyllosomas of Ibacus novemdentatus (Decapoda: Scyllaridae) in a closed recirculating system using jellyfish as food. Aquaculture 330: 162-166.

Wakabayashi K, Tanaka Y (2012) The jellyfish-rider: phyllosoma larvae of spiny and slipper lobsters associated with jellyfish. TAXA: Proceedings of the Japanese Society of Systematic Zoology 33: 5-12 (in Japanese with English abstract)

Yanagihara AA, Kuroiwa JM, Oliver LM, Chung JJ, Kunkel DD (2002) Ultrastructure of a novel eurytele nematocyst of Carybdea alata Reynaud (Cubozoa, Cnidaria). Cell Tissue Res 308: 307-318. 


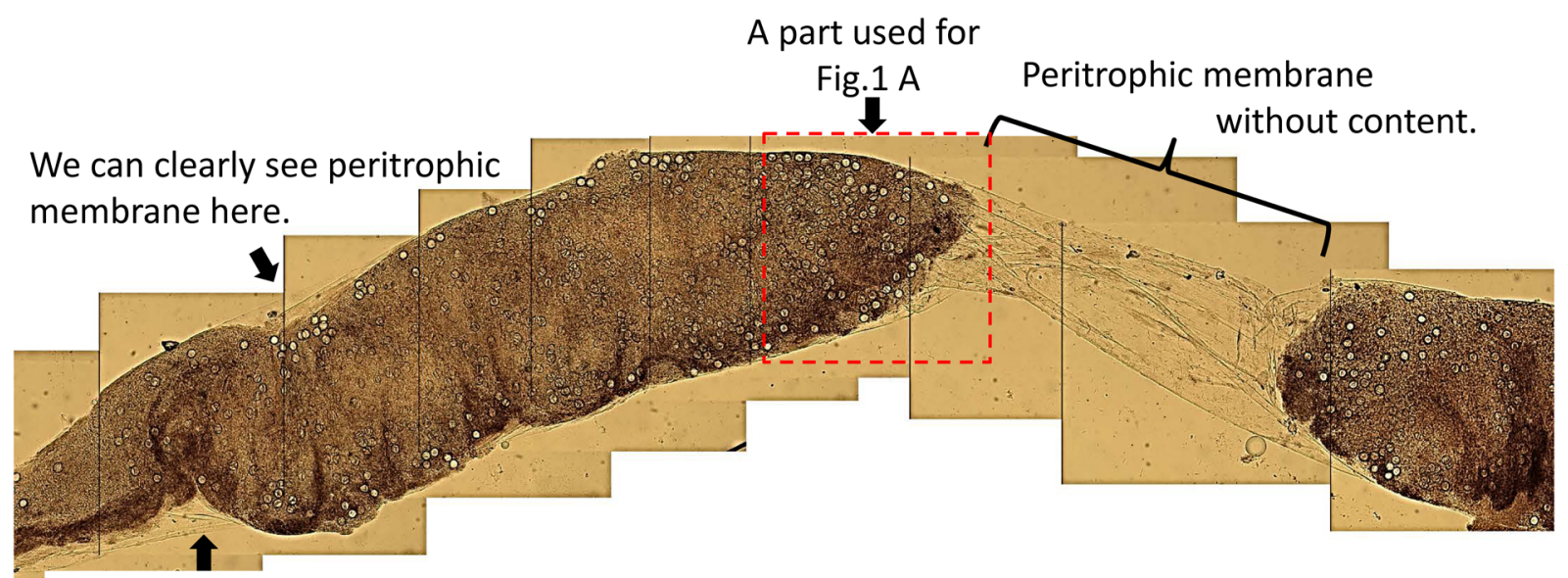

We can clearly see peritrophic membrane here.

Supplemental Figure. 